\title{
PENGARUH LINGKUNGAN KERJA, MOTIVASI, KOMPENSASI TERHADAP KINERJA KARYAWAN MELALUI JOB SATISFACTION PADA KARYAWAN PT BPR BKK TAMAN PERSERODA PEMALANG
}

\author{
Indah Prima Lestari', Djauhar Edi Purnomo², R Irawan $\mathbf{S}^{3}$ \\ 1,3Program Studi S1 Manajemen Fakultas Ekonomika dan Bisnis Universitas \\ muhammadiyah pekajangan pekalongan \\ 2Program Studi D3 Akuntansi Fakultas Ekonomika dan Bisnis Universitas \\ muhammadiyah pekajangan pekalongan \\ Email : r.irawanstiem@gmail.com
}

\begin{abstract}
ABSTRAK
Penelitian ini dilakukan dengan tujuan dan maksud tertentu yaitu, untuk mengetahui pengaruh lingkungan kerja, motivasi dan kompensasi terhadap kinerja melalui Job satisfaction sebagai variabel intervening pada PT BPR BKK TAMAN Perseroda, penelitian ini menggunakan purposive sampling atau sample yang dipilih yaitu 50 responden yang merupakan karyawan PT BPR BKK TAMAN Perseroda, dimana perusahaan ini bergerak pada sektor jasa keuangan. Metode analisis yang di gunakan adalah SEM (Structural Equation Modeling) dengan alat analisis SMartPLS 3 karena kecilnya responden yang dituju, dari hasil penelitian didapatkan bahwa lingkungan kerja berpengaruh secara signifikan terhadap Job satisfaction dan kinerja karyawan, motivasi berpengaruh terhadap Job satisfaction dan kinerja, kompensasi berpengaruh secara signifikan terhadap Job satisfaction terhadap kinerja, Job satisfaction berpengaruh secara signifikan terhadap kinerja, untuk variabel intervening atau Job satisfaction mampu memoderasi variabel eksogen terhadap endogen secara partial
\end{abstract}

Kata kunci: Lingkungan kerja, Motivasi, Kompensasi, kinerja, Job satisfaction

\section{ABSTRACT}

This research was carried out to determine the effect of work environment, motivastion and compensation on performance through job satisfaction as an intervening variable PT BPR BKK TAMAN Perseroda, This study used porposive sampling technique where the selected sample was 50 respondents who were employees of PT BPR BKK TAMAN Perseroda, a financial services provider company, the date were analyzed throught Structural Equation Modeling (SEM), method and SMARTPLS 3 dfe to the small number of targeted respondent from result of the study, it was found that the environment, motivation, and compensation had a significant effect on job satisfaction and employee performance, beside job satisfaction had a significant effect on performance moreover the intervening varable namely job satisfaction could partially moderate exogenous variable

Keyword: work environment, work motivation, compensation, performance, job satisfaction

\section{PENDAHULUAN}

Sumberdaya manusia atau SDM dalam sebuah organisasi atau perusahaan mempunayai peranan yang sangat penting sebagai pemegang hidup dan matinya perusahaan, oleh karena itu perusahaan perlu mempunyai karyawan yang kompeten dan capable dalam melakukan tugasnya dan melaksanakan tujuan organisasi, apalagi sumberdaya manusia di sektor bank 
atau lembaga keuangan yang masuk dalam perusahaan jasa, dalam perusahaan jasa keuangan seperti bank itu kepercayaan dan kepuasan nasabah atau pemakai jasa sangat penting karena bank berjalan berlandaskan kepercayaan, untuk mengetahui seorang karyawan mampu melakukan tugasnya dengan minilai kinerja karyawan, kinerja seorang karyawan bank dinilai langsung oleh nasabah atau konsumen oleh sebab itu perusahaan perlu memperhatikan kinerja karyawan agar citra perusahaan terjaga dan tercapainya tujuan, visi dan misi perusahaan.

Banyak yang bank umum dan juga lembaga keuangan yang mempunyai fungsi yang sama seperti PT BPR BKK TAMAN menjadikan tantangan bagi pihak perusahaan untuk meningkatkan kualitas layanan yang diberikan untuk bisa survive dalam bisnis lembaga keuangan, salah satunya dengan meningkatkan kinerja karyawan, Kinerja yang baik dari seorang karyawan tidak serta merta muncul dengan sendirinya pasti ada faktor yang melatar belakanginya, faktor yang mempengaruhi kinerja adalah lingkunan kerja, motivasi, kompensasi dan kepuasan kerja (Siagian, 2002).

Bedasarkan pernyataan diatas penulis memutuskan membuat rumusan masalah yang betujuan untuk mengetahui faktor yang berpengaruh terhadap peningkatan kinerja karyawan dari PT BPR BKK TAMAN: 1).Apakah lingkungan kerja berpengaruh signifikan terhadap job satisfaction (kepuasan kerja) pada PT BPR BKK TAMAN. 2).Apakah lingkungan kerja bepengaruh signifikan terhadap kinerja karyawan pada PT BPR BKK TAMAN 3).Apakah motivasi kerja berpengaruh signifikan terhadap job satisfaction (kepuasan kerja) pada karyawan PT BPR BKK TAMAN. 4).Apakah motivasi kerja berpengaruh signifikan terhadap kinerja pada karyawan PT BPR BKK TAMAN. 5).Apakah kompensasi berpengaruh signifikan terhadap job satisfaction (kepuasan kerja) pada karyawan PT BPR BKK TAMA. 6).Apakah kompensasi berpegaruh signifikan terhadap kinerja pada karyawan PT BPR BKK TAMAN. 7). Apakah job satisfaction (kepuasan kerja) berpengaruh signifikan terhadap kinerja karyawan PT BPR BKK TAMAN. 8).Apakah lingkungan kerja berpengaruh secara signifikan terhadap kinerja karyawan PT BPR BKK TAMAN melalui job satisfaction (kepuasan kerja). 9).Apakah motivasi berpengaruh secara signifikan terhadap kinerja karyawan PT BPR BKK TAMAN melalui job satisfaction (kepuasan kerja). 10). Apakah kompensasi berpengaruh secara signifikan terhadap kinerja karyawan PT BPR BKK TAMAN melalui job satisfaction (kepuasan kerja)

\subsection{LANDASAN TEORI DAN PENGEMBANGAN HIPOTESIS \\ 1.1.1. KINERJA KARYAWAN}

Kinerja adalah hasil kerja yang dicapai seorang karyawan atau sekelompok orang dalam suatu organisasi perusahaan sesuai dengan wewenang dan tanggung jawab yang diberikan masing masing dalam maksud untuk mencapai tujuan organisasi secara legal (Afandi, 2018) 


\subsubsection{JOB SATISFACTION}

Job satisfaction atau kepuasan kerja adalah keadaan emosianal yang menyanangkan atau tidak menyenangkan dari karyawan dalam memandang atau mengartikan pekerjaan mereka (handoko, 2001), kepuasan juga dapat diartikan perasaan yang positif dari karyawan dalam merasakan pekerjaanya

\subsubsection{LINGKUNGAN KERJA}

Lingkungan kerja adalah kehidupan social psikologi dan fisik dalam sebuah organsiasi atau perusahaan yang berpengaruh pada karyawan dalam melakukan pekerjaan (Komarudin, 2001), dapat dikatakan bahwa lingkungan kerja erat kaitannya dalam mendukung proses pekerjaan untk menghasilkan kinerja yang baik, sebagaii bentuk pencapaian tujuan organisasi.

\subsubsection{MOTIVASI}

Motivasi adalah kondisi yang melatar belakangi sseorang atau karyawan dalam melakukan sebuah kegiatan dari kemampuannya sendiri dalam rangka mencapai tujuan organisasi juga secara bersamaan memenuhi kebutuhan pribadi dan menimbulkan kepuasan dalam diri (Ayub N. \& Rafif, 2011).

\subsubsection{KOMPENSASI}

Kompensasi adalah bentuk balas jasa atau bentuk perusahaan mengapreciate segala keringat darah dan air mata sebagai bentuk kontribusi karyawan dalam perannya melaksanakan rencana guna mencapai tujuan bersama (Laksmi, 2011).

\section{PENELITIAN TERDAHULU}

Dwi maya sari (2016) dengan judul “Analisis Pengaruh Lingkungan Kerja Terhadap Kinerja Karyawan melalui Kepuasan kerja sebagai Variabel Intervening" penelitian ini dilakukan di PT BTN SYARIAH, metode pengambilan data yaitu dengan menyebar kuesioner, dengan uji asumsi klasik, uji analisis berganda dan uji analisis jalur, dengan sample sebanyak 107 responden, alat uji yang digunakan dalam penelitian ini adalah SPSS, penelitian ini dilakukan dengan tujuan untuk mengetahui dan mendapatkan provement bahwasanya lingkungan kerja berpengaruh positi terhadap kepuasan kerja dan dapat menimbulkan kinerja pada PT BNI SYARIAH, perbedaan peelitian ini dengan penelitian terdahulu adalah adanya penambahan varriabel $X$ yaitu motivasi dan kompensasi sserta perbedaan dalam objek penelitian, perbedaan juga ada terletak dari penggunaan alat analisis yaitu SmartPls 3.0 dalam mengolah data. 


\section{KERANGKA PEMIKIRAN}

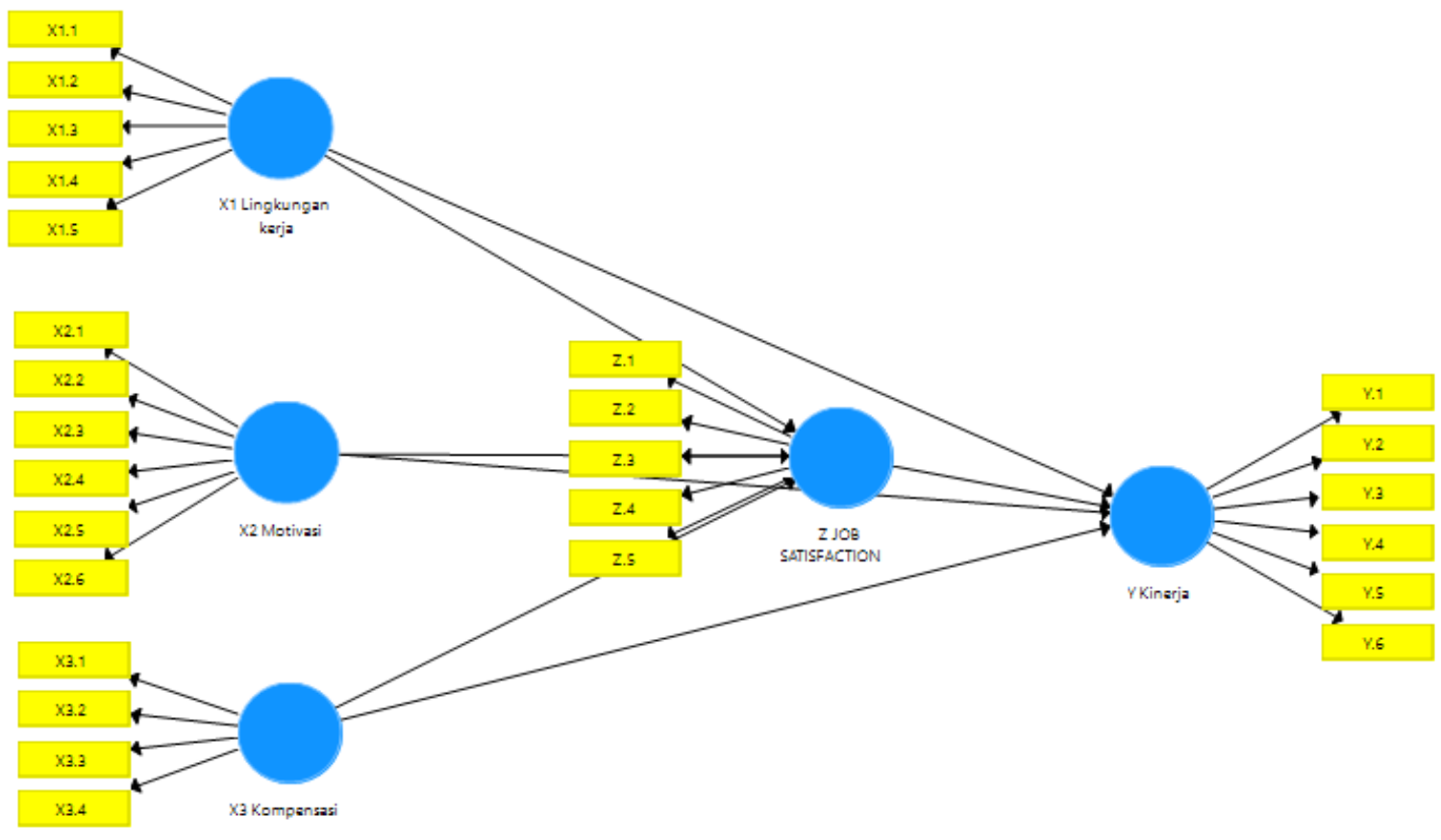

Gambar 3 Gambar dari SMartPLS

\section{HIPOTESIS}

H1: Lingkungan kerja berpengaruh secara signifikan terhadap Job satisfaction (kepuasan kerja)

H2: Lingkungan kerja berpengaruh secara signifikan terhadap kinerja karyawan

H3: Motivasi kerja berpengaruh secara signifikan tehadap Job satisfaction (kepuasan kerja)

H4: Motivasi kerja berpengaruh secara signifikan terhadap Kinerja karyawan

H5: kompensasi berpengaruh secara sinifikann terhadap Job satisfaction (kepuasan kerja)

H6: Kompensasi berpengaruh secara signifikan terhadap kinerja karyawan

H7: Job satisfaction (kepuasan kerja) berpengaruh secara signifikan terhadap kinerja karyawan

H8: lingkungan kerja berpengaruh terhadap kinerja melalui job satisfaction sebagai variabel intervening

H9: Motivasi berpengaruh terhadap Kinerja melalui Job Satisfaction sebagai variable intervening

H10: kompensasi berpengaruh terhadap kinerja karyawan melalui Job satisfaction sebagai Variable intervening

\section{METODE PENELITIAN}

Penelitian ini adalah jenis penelitian kuantitatif, dikarenakan data yang disajikan berupa angka, dengan angka angka tersebut dapat membuktikan dan menjelaskan adanya pengaruh dari variabel dengan variabel lainnya yang diteliti 


\subsection{Populasi dan sampel}

Populasi penelitian adalah karyawan PT BPR BKK TAMAN Perseroda Pemalang, dalam penelitian ini, peneliti menggunakan purposive sampling sebanyak 50 responden, responden yang menjadi objek penelitian adalah karyawan di cabang moga dan cabang pusat, pemilihan ini dikarenakan peneliti mempunyai kriteria kriteria tertentu diantara lain adalah ketatnya persaingan cabang cabang tersebut karena dikelilingi banyaknya lembaga keuangan serta bank umum di sekitarnya.

5.2. Data, Instrumen dan Teknik pengumpulan data

data dalam penelitian ini adalah data primer atau data didapatkan melalui hasil wawancara dan seperangkat pertanyaan yang diberikan oleh peneliti kepada responden dengan indikator pertanyaan sesuai dengan variabel varaibel terkait menggunakan skala likert 1-5.

\subsection{Teknik analisis data}

Penelitian ini selaian menggunakan variabel $X$ dan $Y$ peneliti menggunakan juga variabel $\mathrm{Z}$ oleh karena itu untuk memudahkan peneliti dalam mengolah data yang maka peneliti mengguanakan SEM ( Structural Equation Modeling), karena sampel yang digunakan dibawah 50 maka peneliti memilih menggunakan SMartPls yang bisa merunning data 35- 100 responden.

\section{HASIL DAN PEMBAHASAN}

\subsection{Uji Validitas}

Uji ini dilakukan untuk mengetahui instrument yang digunakan telah valid atau tidak sehingga bisa di gunakan sebagai alat penelitian, dalam SMartPls ada 2 tahapan uji yang dilakukan

6.1.1. Convergent validity

Untuk uji ini harus melihat dari data loading factor dan nilai AVE (Average Variance Extraced)

Tabel 6.1 Analisis Loading factor

\begin{tabular}{|l|r|r|l|l|l|}
\hline & $\begin{array}{c}\text { Lingkungan } \\
\text { Kerja }\end{array}$ & Motivasi & kompensasi & Kinerja & $\begin{array}{c}\text { Job } \\
\text { satisfaction }\end{array}$ \\
\hline X1.1 & 0,838 & & & & \\
\hline X1.2 & 0,904 & & & & \\
\hline X1.3 & 0,897 & & & & \\
\hline X1.4 & 0,917 & & & & \\
\hline X1.5 & 0,886 & & & & \\
\hline X2.1 & & 0,811 & & & \\
\hline X2.2 & & 0,888 & & & \\
\hline X2.3 & & 0,908 & & & \\
\hline X2.4 & & 0,891 & & & \\
\hline X2.5 & & 0,811 & & & \\
\hline X2.6 & & 0,857 & & & \\
\hline
\end{tabular}




\begin{tabular}{|l|l|l|l|l|l|}
\hline$X 3.1$ & & & 0,795 & & \\
\hline$X 3.2$ & & & 0,783 & & \\
\hline$X 3.3$ & & & 0,815 & & \\
\hline$X 3.4$ & & & 0,830 & & \\
\hline$Y .1$ & & & & 0,767 & \\
\hline$Y .2$ & & & & 0,792 & \\
\hline Y.3 & & & & 0,720 & \\
\hline Y.4 & & & & 0,775 & \\
\hline Y.5 & & & & 0,756 & \\
\hline Y.6 & & & & 0,710 & \\
\hline$Z .1$ & & & & & 0,766 \\
\hline$Z .2$ & & & & & 0,700 \\
\hline$Z .3$ & & & & & 0,787 \\
\hline$Z .4$ & & & & & 0,840 \\
\hline$Z .5$ & & & & & 0,809 \\
\hline
\end{tabular}

Dari table diatas loading factor setiap item variabel menunjukan nilai lebih dari 0,7 artinya data tersebut memenuhi syarat untuk uji selanjutnya, setalah loading factor ada uji AVE

Tabel 6.2 Analisis Average Variance Extracted

\begin{tabular}{|l|l|c|}
\hline N0 & Variabel Yang Digunakan & Average Variance Extraced \\
\hline X1 & Lingkungan kerja & 0,790 \\
\hline X2 & Motivasi & 0,743 \\
\hline X3 & Kompensasi & 0,650 \\
\hline Y & Kinerja & 0,568 \\
\hline Z & Job satisfaction & 0,612 \\
\hline
\end{tabular}

Data dari AVE diatas menunujukan nilai lebih dari 0,5 yang dapat disimpulkan bahwa data yang digunakan telah memenuhi syarat dalam uji convergent validity sehingga dapat dilanjutkan pada uji selanjutnya.

6.1.2. Discriminant validity

Dalam discriminant validity uji ini dapat melihat dari nilai cross loading, yaitu nilai per konstruk di korelasikan dengan konstruk yang lain.

Tabel 6.3 Analisis Cross Loading

\begin{tabular}{|c|c|c|c|c|c|}
\hline & $\mathrm{X} 1$ & $\mathrm{X} 2$ & $\mathrm{X} 3$ & $\mathrm{Y}$ & $\mathrm{Z}$ \\
\hline $\mathrm{X} 1.1$ & $\mathbf{0 , 8 3 8}$ & 0,511 & 0,437 & 0,618 & 0,659 \\
\hline $\mathrm{X} 1.2$ & $\mathbf{0 , 9 0 4}$ & 0,613 & 0,534 & 0,696 & 0,610 \\
\hline $\mathrm{X} 1.3$ & $\mathbf{0 , 8 9 7}$ & 0,564 & 0,494 & 0,638 & 0,669 \\
\hline $\mathrm{X} 1.4$ & $\mathbf{0 , 9 1 7}$ & 0,526 & 0,531 & 0,657 & 0,634 \\
\hline $\mathrm{X} 1.5$ & $\mathbf{0 , 8 8 6}$ & 0,545 & 0,560 & 0,710 & 0,665 \\
\hline $\mathrm{X} 2.1$ & 0,462 & $\mathbf{0 , 8 1 1}$ & 0,322 & 0,556 & 0,508 \\
\hline $\mathrm{X} 2.2$ & $\mathbf{0 , 5 4 2}$ & $\mathbf{0 , 8 8 8}$ & 0,260 & 0,608 & 0,525 \\
\hline
\end{tabular}




\begin{tabular}{|c|c|c|c|c|c|}
\hline$X 2.3$ & 0,594 & 0,908 & 0,342 & 0,644 & 0,629 \\
\hline X2.4 & 0,528 & 0,891 & 0,310 & 0,555 & 0,585 \\
\hline $\mathrm{X} 2.5$ & 0,526 & 0,811 & 0,333 & 0,628 & 0,587 \\
\hline$X 2.6$ & 0,553 & 0,857 & 0,328 & 0,536 & 0,479 \\
\hline $\mathrm{X} 3.1$ & 0,508 & 0,258 & 0,795 & 0,568 & 0,490 \\
\hline X3.2 & 0,469 & 0,393 & 0,783 & 0,663 & 0,610 \\
\hline X3.3 & 0,391 & 0,222 & 0,815 & 0,512 & 0,486 \\
\hline X3.4 & 0,482 & 0,285 & 0,830 & 0,601 & 0,516 \\
\hline Y.1 & 0,614 & 0,545 & 0,562 & 0,767 & 0,700 \\
\hline Y.2 & 0,584 & 0,471 & 0,715 & 0,792 & 0,623 \\
\hline Y.3 & 0,535 & 0,595 & 0,330 & 0,726 & 0,580 \\
\hline Y.4 & 0,492 & 0,637 & 0,439 & 0,775 & 0,654 \\
\hline Y.5 & 0,639 & 0,475 & 0,640 & 0,756 & 0,564 \\
\hline Y.6 & 0,540 & 0,390 & 0,601 & 0,735 & 0,612 \\
\hline Z.1 & 0,618 & 0,550 & 0,482 & 0,720 & 0,766 \\
\hline Z.2 & 0,481 & 0,447 & 0,454 & 0,505 & 0,742 \\
\hline Z.3 & 0,587 & 0,473 & 0,527 & 0,672 & 0,787 \\
\hline Z.4 & 0,568 & 0,589 & 0,531 & 0,700 & 0,840 \\
\hline$Z .5$ & 0,585 & 0,451 & 0,577 & 0,643 & 0,809 \\
\hline
\end{tabular}

Dari data cross loading didapatkan hasil yang valid dikarenakan setiap konstruk indikator memiliki nilai paling besar jika dikorelasikan dengan konstruk itu sendiri dibandingkan dengan konstruk yang lain.

6.2. Uji Reabilitas

Syarat pada uji reabilitas adalah dengan melihat nilai data Cronbach alpha dan nilai composite reability

Tabel 6.4 Analisis Cronbach Alpha dan Composite Reability

\begin{tabular}{|l|c|c|c|}
\hline NO & Cronbach's Alpha & Rho-A & Composite Reability \\
\hline X1 & 0,933 & 0,934 & 0,949 \\
\hline X2 & 0,930 & 0,933 & 0,945 \\
\hline X3 & 0,821 & 0,824 & 0,824 \\
\hline Y & 0,848 & 0,851 & 0,888 \\
\hline Z & 0,840 & 0,846 & 0,887 \\
\hline
\end{tabular}

Dari data diatas menunjukan nilai Conbrach's Alpha lebih dari 0,7 dan composite reability lebih dari 0,8 yang berarti data yang kita miliki mempunyai nilai yang reabel.

6.3. Model Struktural

Adalah model yang menggambarkan hubungan kausalitas antar variabel laten dalam uji ini ada beberapa uji yang dilakukan seperti uji arah hubungan positif atau negatif, dan uji hipotesis dengan uji $t$ atau sigifikansi didalamnya. 
6.4. R Square

Nilai dari R Square adalah nilai Variabel dependen atau endogen dan nilai dari variabel intervening atau moderating

Tabel 6.5. Analisis R-Square

\begin{tabular}{|l|c|c|}
\hline & R-SQUARE & R Square Ajusted \\
\hline $\mathrm{Y}$ & 0,818 & 0,801 \\
\hline $\mathrm{Z}$ & 0,674 & 0,653 \\
\hline
\end{tabular}

Dari data diatas dapat ditarik kesimpulan variabel $\mathrm{Y}$ atau Kinerja mempunyai nilai 0,801 atau jika dipresentasikan maka nilainya ialah $80 \%$ yang berarti $80 \%$ kinerja dipengaruhi dari lingkungan kerja, motivasi, kompensasi dan job satisfaction variabel Z ikut mempengaruhi karena variable $Z$ atau variable intervening bisa dikatakan as predictor atau yang mempengaruhi, sedangkan $20 \%$ nya lagi dipengaruhi oleh variabel lain yang tidak diteliti, sedangkan untuk variabel intervening sendiri atau job satisfaction mempunyai nilai 0,653, yang dapat dipresentasikan menjadi 65\% dari $100 \%$ dipengaruhi oleh lingkungan kerja, motivasi dan kompensasi, sedangkan 35\% lagi dipengaruhi oleh variable lain yang tidak diteliti.

6.5. Path Coefficient

Tabel 6.6 Analisis Path Coefficient

\begin{tabular}{|l|c|c|}
\hline & Y Kinerja & Z Job satisfaction \\
\hline X1 & 0,167 & 0,334 \\
\hline X2 & 0,238 & 0,308 \\
\hline X3 & 0,320 & 0,352 \\
\hline Z & 0,363 & \\
\hline
\end{tabular}

Untuk menentukan positif dan negatifnya suatu arah hubungan yaitu dengan nilai hubungan lebih dari 0 dari, dari table diatas X1 terhadap Y mempunyai nilai 0,167 > 0 maka hubungannya positif, untuk $X 2$ terhadap $Y$ mempunyai nilai $0,238>0$ positif, $X 3$ terhadap $Y$ mempunyai nilai 0,320 bererti arah hubungannya positif, untuk $Z$ atau job satisfaction mempunyai nilai lebih dari 0 yaitu 0,363 berarti arah hubungannya positif, sedangkan variable eksogen atau independen terhadap variable intervening atau $\mathrm{Z}$ ya pertama $\mathrm{X} 1$ mempunyai nilai 0,334 berarti arah hubungannya positif, untuk X2 terhadap Z mempunyai nilai 0,308 berarti nilai hubungannya positih untuk variabel $X 3$ memiliki hubungan yang positif karena mempunyai nilai 0,352

6.6. Uji T Statistic (Bootstrapping)

Uji $\mathrm{T}$ statistic adalah uji signifikansi untuk melihat hipotesis diterima atau tidak diterima dengan nilai $\mathrm{T}$ statistic dan $\mathrm{p}$ value, untuk $\mathrm{p}$ value atau nilai probability. 
Tabel 6.7 Analisis Boot Strapping

\begin{tabular}{|c|c|c|c|c|c|}
\hline Hubungan & $\begin{array}{c}\text { Original } \\
\text { sampel }\end{array}$ & $\begin{array}{c}\text { Sample } \\
\text { Mean }\end{array}$ & $\begin{array}{c}\text { Standart } \\
\text { Deviation }\end{array}$ & T Statistic & P Value \\
\hline $\mathrm{X} 1 \_>$Z & 0,334 & 0,164 & 0,067 & 2,453 & 0.014 \\
\hline $\mathrm{X} 1 \_$Y Y & 0,167 & 0,313 & 0,136 & 2,461 & 0,014 \\
\hline $\mathrm{X} 2->\mathrm{Z}$ & 0,308 & 0,236 & 0,096 & 2,489 & 0,013 \\
\hline $\mathrm{X} 2->\mathrm{Y}$ & 0,238 & 0,328 & 0,108 & 3,091 & 0,002 \\
\hline $\mathrm{X} 3->\mathrm{Z}$ & 0,352 & 0,316 & 0,114 & 2,813 & 0,005 \\
\hline $\mathrm{X} 3->Y$ & 0,320 & 0,361 & 0,137 & 2,589 & 0,010 \\
\hline Z-> Y & 0,363 & 0,353 & 0,088 & 4,015 & 0,000 \\
\hline
\end{tabular}

Pengolahan data diatas menunjukan bahwa semua variable $\mathrm{X}, \mathrm{Y}$ dan $\mathrm{Z}$ berpengaruh positif dan signifikan karena $\mathrm{T}$ statisticnya lebih dari 2,010 $\mathrm{T}$ statistic ini didapatkan dari rumus TINV(probability;DF) yaitu $\operatorname{TINV}(0,05 ; 48)$ kenapa 0,05 adalah Pvalue yang artinya, bahwa lingkungan kerja,motivasi dan kompensasi berpengaruh secara positif dan signifikan pada variabel endogen dan moderating atau berpengaruh pada kinerja dan job satisfaction. Untuk melihat pengaruh dari variabel intervening memoderasi atau tidak dapat dilihat dari hasil pengolahan pada Specific Indirect Effect sebagai berikut

Tabel 6.8 Analisis Speciffic Indirect Effect

\begin{tabular}{|l|c|c|c|c|c|}
\hline Hubungan & $\begin{array}{l}\text { Original } \\
\text { sample }\end{array}$ & $\begin{array}{l}\text { Sample } \\
\text { Mean }\end{array}$ & $\begin{array}{l}\text { Standart } \\
\text { Deviation }\end{array}$ & T ssatistic & P Value \\
\hline X1->Z->Y & 0,118 & 0,111 & 0,057 & 2,069 & 0,040 \\
\hline X2-.Z-.Y & 0,109 & 0,116 & 0,050 & 2,170 & 0,031 \\
\hline X3-.Z-.Y & 0,124 & 0,128 & 0,056 & 2,236 & 0,026 \\
\hline
\end{tabular}

Data yang menunjukan seberapa pengaruhnya variable intervening apakah $\mathrm{Z}$ bisa memoderasi $\mathrm{X}$ dan $\mathrm{Y}$ pada original sample sebenarnya sama dengan path koefisien atau menunjukan arah positif negative sebuah hubungan, untuk arah hubungan semua variabel postif dan $\mathrm{t}$ statistic menunjukan bahwa hasilnya signifikan berarti variable $Z$ dapat memoderating antara variable $X$ dan $Y$.

Hasil yang didapatkan pada kofiseien jalur dengan specific indirect effect tentunya sudah berubah namun hasilnya tetap sama berpengaruh dan signifikan, dapat disimpulkan bahwa variable $\mathrm{Z}$ pada penelitian ini adalah partial mediation, partial mediation adalah dimana ada atau tidak adanya variable moderasi atau inetervening variabel eksogen masih bisa mempengaruhi variable endogen.

\section{KESIMPULAN DAN SARAN}

7.1. Kesimpulan

7.1.1. Variable eksogen lingkungan kerja atau X1 memiliki hasil arah yang positif atau berpengaruh secara signifikan terhadap job satisfaction 
karena nilai original sample $0,334>0$ dan $\mathrm{T}$ statistic 2,453 $>2,010$ serta $P$ value $0,014<0,05$

7.1.2. Lingkungan kerja berpengaruh secara signifikan terhadap kinerja karyawan karena memiliki hasil original sample 0,167 $>0$ denga $\mathrm{t}$ statistic 2,461 > 2,010 dan $p$ value 0,014<0,05

7.1.3. Motivasi berpengaruh secara signifika terhadap job satisfaction bedasarkan dari hasil original sample $0,308>0$ dengan $\mathrm{T}$ statistic $2,489>2,010$ dengan $p$ value $0,013<0,05$

7.1.4. Motivasi berpengaruh secara siginifikan terhadap kinerja karyawan karena menghasilkan data original sample $0,238>0$ dengan $\mathrm{T}$ statistic $3,091>2,010$ dengan $p$ value 0,002

7.1.5. Kompensasi berpengaruh secara signifikan terhadap Job satisfaction bedasarkan hasil yang diperoleh original sample 0,352 $>0$ dega $\mathrm{T}$ statistic 2,813 >2,010 dengan $p$ value 0,005

7.1.6. Kompensasi berpengaruh secara signifikan terhadap Kinerja bedasarkan hasil dari original sample $0,320>0$ denga T statistic 2,589 $<2,010$ dengan $p$ value $0,010<0,05$

7.1.7. Job satisfaction berpengaruh secara signifikan terhadap Kinerja karyawan bedasarkan hasil dari original sampel $0,363>0$ dan $T$ statistic 4,015 >2,010 dan $p$ value 0,000 kurang dari 0,05

7.1.8. Lingkungan kerja berpengaruh secara signifikan terhadap Kinerja melalui Job satisfaction sebagai variable intervening dengan hasil analisis original sample $0,118>0$ dan $T$ statistic 2,069>2,010dengan $p$ value 0,040

7.1.9. Motivasi berpengaruh secara signifikan terhadap Kinerja melalui Job satisfactiondengan hasil original sample 0,109>0 dan $\mathrm{T}$ statistic $2,170>2,010$ dengan $p$ value $0,031<0,05$

7.1.10. Kompensasi berpengaruh secara signifkan terhadap kinerja karyawan melalui Job satisfaction original sample $0,124>0$ dan $\mathrm{T}$ statistic 2,236 $>2,010$ dengan $p$ value $0,026<0,05$

7.2. Saran

7.2.1. Untuk Objek Penelitian

Untuk pihak PT BPR BKK TAMAN, lebih memperhatikan kepuasan motivasi dan mempertimbangkan system kompensasi yang lebih sepadan, yang terpenting adalah lingkungan kerja bagaimana bisa pemimpin memepengaruhi karyawan dalam menciptakan vibe positive baik pegawai antar pegawai maupun pegawai dengan pimpinan

7.2.2. Untuk Penelitian Selanjutnya

Untuk saran pada penelitian selanjutnya jika di dalam objek peenelitian memiliki masalah yang sama dengan penelitian ini yaitu tekanan target karena bekerja di dalam lembaga keuangan maka lebih baik menambah variable eksogen seperti stress kerja,dan juga dilihat alat analisinya sudah bisa mendukung dan memenuhi serta menjawab hipotesis yang didapatkan 


\section{REFERENSI}

Afandi, P. (2018 ). Manajemen Sumber Daya Manusia Teori Konsep dan indikator . Riau: Zanafa Publishing.

Ayub N. \& Rafif, S. (2011). The Relationship between work motivation and job satisfaction . Pakistan Business Review, 332-347.

handoko. (2001). T Hani Handoko. In manajemen personalia dan sumber daya manusia edisi 2 (p. 208). Yogyakarta : BPFE.

Komarudin. (2001). Ensikklopedia manajemen edisi 5 . Jakarta: Bumi Aksara.

Laksmi, A. (2011). Prespektif Kompensasi. Jawa Tengah: YUMA Pustaka.

Siagian, S. P. (2002). Manajemen Sumber Daya manusia . Jakarta : Bumi Aksara . 